\title{
Dispersion OF AERosols in AtMospheric FluID FLOW
}

\author{
Meena Priya.P \\ Mathematics Section, Faculty of Engineering and Technology, \\ Annamalai University, India
}

\begin{abstract}
A mathematical model is presented in this paper to study the dispersion of aerosols with and without chemical reaction in the presence of electric and magnetic field. The Taylor dispersion coefficient is determined and are numerically computed for different values of reaction rate, electric and Hartmann numbers. The results are depicted graphically and conclusions are drawn in the final section.
\end{abstract}

\section{KEYWORDS}

Fluid, Concentration of aerosol, Chemical reaction, Taylor dispersion model

\section{INTRODUCTION}

In recent years, considerable interest has been evinced in the study of dispersion of aerosols in a horizontal or vertical channel, because of their importance in many applications like in biomedical engineering, environmental pollution, material science processing and so on. Aerosols are defined as liquid or solid particles suspended in the medium of air. Earth's atmosphere contains a variety of particles with varying size, shape and chemical composition. These particles are suspended in air for varying time periods, from a few minutes to about a week and are transported by winds to long distances. Aerosol particles occur in great amount near the earth's surface and their concentration decreases rapidly with increasing altitude. Several reports are available for the distribution of aerosols over the globe (Ansmann et al., 2000; Muller et al., 2001; Ramana et al., 2004; Tripathi et al., 2005; Satheesh et al., 2006; Niranjan et al., 2007).

Electromagnetohydrodynamics (usually shortened to EMHD) is the fluid mechanics of electrically conducting fluids. Atmospheric electricity abounds in the environment. Some traces of it are found less than four feet from the surface of the earth, but an attaining greater height it becomes more apparent. The electrical forces also play the significant role in the development of thunderstorms. Electric currents induced in the atmosphere generate magnetic field. Several investigations are carried out on the problem of magnetohydrodynamic flow of a viscous incompressible fluid considering various variations in the problem. Guria et al. (2009) investigated the oscillatory MHDCouette flow of electrically conducting fluid between two parallel plates in a rotating system in the presence of an inclined magnetic field. Das et al. (2009) studied unsteady hydromagnetic couette flow of a viscous incompressible electrically conducting fluid in a rotating system.

Understanding the phenomenon on dispersion under the combined influence of convection and diffusion is of considerable value in many fields. The earlier work on dispersion by Taylor 
International Journal of Soft Computing, Mathematics and Control (IJSCMC), Vol. 4, No. 2, May 2015

(1953) is mainly valid for large time after injecting a solute into a medium. Shivakumar et al. (1987) developed this model to study dispersion in porous media valide for all time. The combined effects of homogeneous and heterogeneous reactions on the dispersion of a solute in a liquid flowing between two parallel plates in the presence of an irreversible first-order chemical reaction is studied using Taylor dispersion model by Gupta and Gupta (1972). Dispersion with chemical reaction has been developed by many authors (Pal, 1999; Rudraiah and Ng, 2007; Meena Priya and Nirmala P.Ratchagar, 2012).

In recent years, the study of a chemically reactive pollutant has generated considerable attention because of its harmful effects. Kazuhide Ito and Hiroshi Harashima (2011) investigated coupled CFD analysis of size distributions on indoor secondary organic aerosol derived from ozone.

Anttilla et al. (2006) studied the reactive uptake of gaseous compounds by organic-coated aerosols. Brasseur et al. (2006) have analysed the impact of climate change on the future chemical composition of the global troposphere. Stier et al. (1996) considered the physical characterization of aerosols and heterogeneous reactions in a large atmospheric chamber. The objective of this work is to present the dispersion of aerosols with and without chemical reaction under the effects of applied electric and magnetic field using Taylor's model.

\section{MATHEMATICAL FORMULATION}

We consider two-dimensional laminar incompressible viscous flow of aerosols as shown in figure 1. It consists of an infinite horizontal atmospheric fluid layer bounded on both sides by electroconducting impermeable rigid plates embedded with electrodes located at $\mathrm{y}=0$ and $\mathrm{y}=\mathrm{h}$ with an applied magnetic field $\mathrm{B}_{0}$. On the boundaries, the electric potentials $\phi=\frac{\mathrm{V}}{\mathrm{h}} \mathrm{x}$ at $\mathrm{y}=0$ and $\phi=\frac{\mathrm{V}}{\mathrm{h}}\left(\mathrm{x}-\mathrm{x}_{0}\right)$ at $\mathrm{y}=\mathrm{h}$ are maintained on these boundaries where $\mathrm{V}$ is potential.

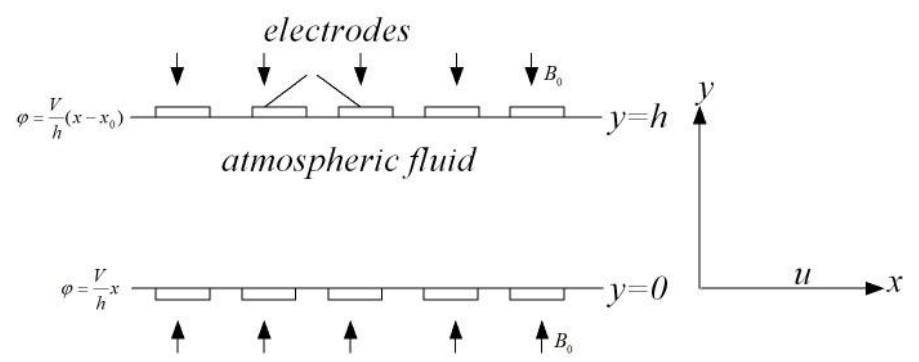

Figure 1. Physical configuration

We consider very small electrical conductivity $(\sigma)$ so that we can easily neglect the induced magnetic field. It makes the electric field $\overrightarrow{\mathrm{E}}$, to be conservative.

$$
\text { i.e. } \vec{E}=-\nabla \phi
$$

The conservation of mass for an incompressible fluid

$$
\nabla \cdot \vec{q}=0
$$


The conservation of momentum

$$
\rho\left(\frac{\partial \overrightarrow{\mathrm{q}}}{\partial \mathrm{t}}+(\overrightarrow{\mathrm{q}} \cdot \nabla) \overrightarrow{\mathrm{q}}\right)=-\nabla \mathrm{p}+\mu \nabla^{2} \overrightarrow{\mathrm{q}}+\rho_{\mathrm{e}} \overrightarrow{\mathrm{E}}+\mu(\overrightarrow{\mathrm{J} x} \overrightarrow{\mathrm{B}})
$$

where $\overrightarrow{\mathrm{q}}$ the velocity, $\mathrm{p}$ the pressure, $\mu$ the viscosity, $\rho_{\mathrm{e}}$ the density of the charge distribution, $\overrightarrow{\mathrm{E}}$ the electric field, $\overrightarrow{\mathrm{J}}$ the current density and $\overrightarrow{\mathrm{B}}$ the magnetic induction.

The conservation of species

$$
\frac{\partial \mathrm{C}}{\partial \mathrm{t}}+(\overrightarrow{\mathrm{q}} \cdot \nabla) \mathrm{C}=\mathrm{D} \nabla^{2} \mathrm{C}
$$

The conservation of charges

$$
\frac{\partial \rho_{\mathrm{e}}}{\partial \mathrm{t}}+(\overrightarrow{\mathrm{q}} \cdot \nabla) \rho_{\mathrm{e}}+\nabla \cdot \overrightarrow{\mathrm{J}}=0
$$

The Maxwell's equations

$$
\begin{aligned}
& \nabla \cdot \overrightarrow{\mathrm{E}}=\frac{\rho_{\mathrm{e}}}{\varepsilon_{0}} \\
& \nabla \times \overrightarrow{\mathrm{E}}=\frac{-\partial \overrightarrow{\mathrm{B}}}{\partial \mathrm{t}} \\
& \overrightarrow{\mathrm{J}}=\sigma \overrightarrow{\mathrm{E}}
\end{aligned}
$$

where $\varepsilon_{0}$ the dielectric constant and $\sigma$ the electrical conductivity. The above equations are solved using the following boundary conditions on velocity are,

$$
\left.\begin{array}{ll}
\mathrm{u}=0 \text { at } & \mathrm{y}=0 \\
\mathrm{u}=0 \text { at } & \mathrm{y}=\mathrm{h}
\end{array}\right\}
$$

The boundary conditions on electric potential are,

$$
\left.\begin{array}{ll}
\phi=\frac{\mathrm{V}}{\mathrm{h}} \mathrm{x} \text { at } & \mathrm{y}=0 \\
\phi=\frac{\mathrm{V}}{\mathrm{h}}\left(\mathrm{x}-\mathrm{x}_{0}\right) \text { at } & \mathrm{y}=\mathrm{h}
\end{array}\right\}
$$

In cartesian form, using the above approximation equation (3) becomes

$$
0=-\frac{\partial p}{\partial x}+\mu \nabla^{2} u+W e \rho_{e} E_{x}-M^{2} u, \nabla^{2}=\frac{\partial^{2}}{\partial y^{2}}
$$


where $M^{2}=\frac{\sigma B_{0}^{2} h^{2}}{\mu}\left(M\right.$ is the Hartmann number), $B_{0}$ the uniform applied magnetic field, $\sigma$ the electrical conductivity and $\mu$ the coefficient of viscosity. In a poorly conducting fluid, the electrical conductivity is assumed to vary linearly with temperature and increases with temperature in the form

$$
\sigma=\sigma_{0}\left[1+\alpha_{h}\left(T_{b}-T_{0}\right)\right]
$$

where $\alpha_{\mathrm{h}}$ is the volumetric coefficient of expansion.

After making dimensionless, using

$$
\mathrm{y}^{*}=\frac{\mathrm{y}}{\mathrm{h}} ; \mathrm{u}^{*}=\frac{\mathrm{u}}{\frac{v}{\mathrm{~h}}} ; \quad \mathrm{E}_{\mathrm{x}}^{*}=\frac{\mathrm{E}_{\mathrm{x}}}{\frac{v}{\mathrm{~h}}} ; \rho_{\mathrm{e}}^{*}=\frac{\rho_{\mathrm{e}}}{\frac{\varepsilon_{0} v}{\mathrm{~h}^{2}}} ; \quad \mathrm{P}^{*}=\frac{\mathrm{P}}{\rho\left(\frac{v}{\mathrm{~h}}\right)^{2}} ; \mathrm{x}^{*}=\frac{\mathrm{x}}{\mathrm{h}} ;
$$

where $\mathrm{V}$ is electric potential, we get electric potential through electrodes.

Equations (3) to (11) becomes,

$$
\frac{d^{2} u}{d y^{2}}-M^{2} u=W_{e} \rho_{e} E_{x}+P
$$

where $\mathrm{W}_{\mathrm{e}}=\frac{\varepsilon_{0} \mathrm{~V}^{2}}{\mu}, \quad \mathrm{P}=\frac{-\partial \mathrm{p}}{\partial \mathrm{x}}$,

Equation (5) becomes, $\nabla \cdot \vec{J}=0$

Using equation (1) we get,

$$
\sigma\left(\nabla^{2} \phi\right)+\nabla \phi . \nabla \sigma=0
$$

After dimensionless the boundary conditions on velocity and electric potential are

$$
\begin{aligned}
& \mathrm{u}=0 \text { at } \mathrm{y}=0\} \\
& \mathrm{u}=0 \text { at } \mathrm{y}=1\} \\
& \phi=\mathrm{x} \text { at } \quad \mathrm{y}=0\} \\
& \left.\phi=\mathrm{x}-\mathrm{x}_{0} \text { at } \mathrm{y}=1\right\}
\end{aligned}
$$

The electrical conductivity $\sigma$ is negligibly small, $\sigma \ll 1$ and it depends on the conduction temperature $\mathrm{T}_{\mathrm{b}}$ namely,

$$
\frac{d^{2} T_{b}}{d y^{2}}=0
$$

using the boundary conditions 
International Journal of Soft Computing, Mathematics and Control (IJSCMC),Vol. 4, No. 2, May 2015

$$
\left.\begin{array}{ll}
\mathrm{T}_{\mathrm{b}}=\mathrm{T}_{0} \text { at } & \mathrm{y}=\mathrm{0} \\
\mathrm{T}_{\mathrm{b}}=\mathrm{T}_{1} \text { at } & \mathrm{y}=\mathrm{h}
\end{array}\right\}
$$

is $\mathrm{T}_{\mathrm{b}}-\mathrm{T}_{0}=\Delta \mathrm{T}_{\mathrm{y}}$

equation (11) becomes

$$
\begin{aligned}
& \sigma=\sigma_{0}\left[1+\alpha_{\mathrm{h}} \Delta \mathrm{T}_{\mathrm{y}}\right]=\sigma_{0}(1+\alpha \mathrm{y})=\sigma_{0} \mathrm{e}^{\alpha \mathrm{y}} \\
& \sigma \approx \mathrm{e}^{\alpha \mathrm{y}}
\end{aligned}
$$

where $\alpha=\alpha_{\mathrm{h}} \nabla \mathrm{T}$.

Then (13) using (19) we get

$$
\frac{d^{2} \phi}{d y^{2}}+\alpha \frac{d \phi}{d y}=0
$$

The solution for $\phi$ satisfying the boundary equation (15) is

$$
\phi=\mathrm{x}-\frac{\mathrm{x}_{0}}{1-\mathrm{e}^{-\alpha}}\left[1-\mathrm{e}^{-\alpha \mathrm{y}}\right]
$$

Using the non-dimensional quantities and equation (21), equations (6), (7) and (8) reduce to

$$
\rho_{\mathrm{e}}=\nabla \cdot \overrightarrow{\mathrm{E}}=-\nabla^{2} \phi=-\frac{\mathrm{x}_{0} \alpha^{2} \mathrm{e}^{-\alpha \mathrm{y}}}{1-\mathrm{e}^{-\alpha}} ; \mathrm{E}_{\mathrm{x}}=-1
$$

Then

$$
\rho_{\mathrm{e}} \mathrm{E}_{\mathrm{x}}=\frac{\mathrm{x}_{0}^{2} \alpha^{2} \mathrm{e}^{-\alpha y}}{1-\mathrm{e}^{-\alpha}}
$$

\section{ELECTROMAGNETOHYDRODYNAMIC DISPERSION OF AEROSOLS}

The solution of equation (12) satisfying the condition (14) is

$$
\mathrm{u}=\mathrm{A} \cosh \mathrm{My}+\mathrm{B} \sinh \mathrm{My}+\frac{\mathrm{W}_{\mathrm{e}} \mathrm{a}_{0} \mathrm{e}^{-\alpha y}}{\left(\alpha^{2}-\mathrm{M}^{2}\right)}-\frac{\mathrm{P}}{\mathrm{M}^{2}}
$$

where $\mathrm{a}_{0}=\frac{\mathrm{W}_{\mathrm{e}} \mathrm{x}_{0} \alpha^{2}}{\mathrm{e}^{-\alpha}-1} ; \mathrm{A}=\frac{\mathrm{P}}{\mathrm{M}^{2}}-\frac{\mathrm{W}_{\mathrm{e}} \mathrm{a}_{0} \mathrm{e}^{-\alpha \mathrm{y}}}{\left(\alpha^{2}-\mathrm{M}^{2}\right)} ;$

$$
B=\frac{1}{\operatorname{Sinh} M}\left(\frac{P}{M^{2}}(1-\operatorname{Cosh} M)-\frac{W_{e} a_{0} e^{-\alpha y}}{\left(\alpha^{2}-M^{2}\right)}\left(e^{-\alpha}-\operatorname{Cosh} M\right)\right)
$$

The average velocity is given by, 
International Journal of Soft Computing, Mathematics and Control (IJSCMC),Vol. 4, No. 2, May 2015

$$
\begin{aligned}
& \overline{\mathrm{u}}=\int_{0}^{1} \mathrm{udy} \\
& \overline{\mathrm{u}}=\frac{\mathrm{ASinh} M}{\mathrm{M}}-\frac{\mathrm{BCosh} M-1}{\mathrm{M}}+\frac{\mathrm{W}_{\mathrm{e}} \mathrm{a}_{0}}{\alpha\left(\alpha^{2}-\mathrm{M}^{2}\right)}\left(\mathrm{e}^{-\alpha}-1\right)-\frac{\mathrm{P}}{\mathrm{M}^{2}}
\end{aligned}
$$

The concentration of aerosol $\mathrm{C}$ with chemical reaction $\mathrm{K}$ in the atmosphere which diffuse in a fully developed flow can be written as

$$
\frac{\partial \mathrm{C}}{\partial \mathrm{t}}+\mathrm{u} \frac{\partial \mathrm{C}}{\partial \mathrm{x}}=\mathrm{D}\left(\frac{\partial^{2} \mathrm{C}}{\partial \mathrm{x}^{2}}+\frac{\partial^{2} \mathrm{C}}{\partial \mathrm{y}^{2}}\right)-\mathrm{KC}
$$

The longitudinal diffusion is very much less than the transverse diffusion which implies $\frac{\partial^{2} \mathrm{C}}{\partial \mathrm{x}^{2}} \ll \frac{\partial^{2} \mathrm{C}}{\partial \mathrm{y}^{2}}$

Equation (25) becomes

$$
\frac{\partial \mathrm{C}}{\partial \mathrm{t}}+\mathrm{u} \frac{\partial \mathrm{C}}{\partial \mathrm{x}}=\mathrm{D} \frac{\partial^{2} \mathrm{C}}{\partial \mathrm{y}^{2}}-\mathrm{KC}
$$

The dimensionless boundary conditions on concentrations are

$$
\left.\begin{array}{rr}
\frac{\partial C}{\partial y}=0 \text { at } & y=0 \\
\text { and } C=1 \text { at } & y=1
\end{array}\right\}
$$

We introduce the following non-dimensional variables,

$$
\mathrm{y}^{*}=\frac{\mathrm{y}}{\mathrm{h}} ; \mathrm{C}^{*}=\frac{\mathrm{C}}{\mathrm{C}_{0}} ; \mathrm{t}^{*}=\frac{\mathrm{t}}{\mathrm{t}} ; \xi=\frac{\mathrm{x}-\overline{\mathrm{ut}}}{\mathrm{L}} ; \beta^{2}=\frac{\mathrm{h}^{2}}{\mathrm{D}} \mathrm{K}
$$

where $\mathrm{L}$ is the characteristic length along the flow direction and $\beta$ is the dimensionless reaction rate parameter. Equation (26) in dimensionless form can be written as

$$
\frac{1}{\overline{\mathrm{t}}} \cdot \frac{\partial \mathrm{C}^{*}}{\partial \mathrm{t}^{*}}+\frac{(\mathrm{u}-\overline{\mathrm{u}})}{\mathrm{L}} \cdot \frac{\partial \mathrm{C}^{*}}{\partial \xi}=\frac{\mathrm{D}}{\mathrm{h}^{2}} \cdot \frac{\partial^{2} \mathrm{C}^{*}}{\partial \mathrm{y}^{* 2}}-\frac{\beta^{2} \mathrm{D}}{\mathrm{h}^{2}} \mathrm{C}
$$

For simplicity, neglecting the asterisks $(*)$ we get

$$
\frac{1}{\overline{\mathrm{t}}} \cdot \frac{\partial \mathrm{C}}{\partial \mathrm{t}}+\frac{\mathrm{V}}{\mathrm{L}} \cdot \frac{\partial \mathrm{C}}{\partial \xi}=\frac{\mathrm{D}}{\mathrm{h}^{2}} \cdot \frac{\partial^{2} \mathrm{C}}{\partial \mathrm{y}^{2}}-\frac{\beta^{2} \mathrm{D}}{\mathrm{h}^{2}} \mathrm{C}
$$

Where

$$
\mathrm{V}=\mathrm{u}-\overline{\mathrm{u}}=\mathrm{A} \cosh \mathrm{My}+\mathrm{B} \sinh \mathrm{My}+\frac{\mathrm{W}_{\mathrm{e}} \mathrm{a}_{0} \mathrm{e}^{-\alpha \mathrm{y}}}{\left(\alpha^{2}-\mathrm{M}^{2}\right)}+\mathrm{f}
$$


where $\mathrm{f}=-\frac{\mathrm{ASinhM}}{\mathrm{M}}-\frac{\mathrm{BCosh} \mathrm{M}-1}{\mathrm{M}}+\frac{\mathrm{W}_{\mathrm{e}} \mathrm{a}_{0}}{\alpha\left(\alpha^{2}-\mathrm{M}^{2}\right)}\left(\mathrm{e}^{-\alpha}-1\right)$

To obtain $\mathrm{C}$ as the variation of $\mathrm{y}$ by approximating equation (28) in the form

$$
\frac{\partial^{2} \mathrm{C}}{\partial \mathrm{y}^{2}}-\beta^{2} \mathrm{C}=\mathrm{QV}
$$

where $\mathrm{Q}=\frac{\mathrm{h}^{2}}{\mathrm{DL}} \frac{\partial \mathrm{C}}{\partial \xi}$ and $\beta$ the reaction rate parameter.

We consider two cases. First in the presence of chemical reaction and the second without chemical reaction.

\section{Case 1: $\beta \neq 0$ (with chemical reaction)}

Using the equation (29) and satisfying the boundary condition (27), the solution of equation (30) we get

$$
\begin{aligned}
& \mathrm{C}=\mathrm{Q}(\mathrm{C} 1 \operatorname{Cosh} \beta \mathrm{y}+\mathrm{C} 2 \operatorname{Sinh} \beta \mathrm{y}+ \\
& \left.\quad \frac{\mathrm{A} \operatorname{CoshMy}}{\mathrm{M}^{2}-\beta^{2}}+\frac{\mathrm{BSinhMy}}{\mathrm{M}^{2}-\beta^{2}}+\frac{\mathrm{W}_{\mathrm{e}} \mathrm{a}_{0}}{\left(\alpha^{2}-\mathrm{M}^{2}\right)\left(\alpha^{2}-\beta^{2}\right)} \mathrm{e}^{-\alpha y}-\frac{\mathrm{f}}{\beta^{2}}\right)
\end{aligned}
$$

Where

$$
\begin{aligned}
& \mathrm{C} 1=\frac{1}{\operatorname{Cosh} \beta}\left(1-\frac{\mathrm{B}}{\mathrm{M}^{2}-\beta^{2}}\left(\frac{-\mathrm{MSinh} \beta}{\beta}+\operatorname{Sinh} \mathrm{M}\right)-\frac{\mathrm{W}_{\mathrm{e}} \mathrm{a}_{0}}{\left(\alpha^{2}-\mathrm{M}^{2}\right)\left(\alpha^{2}-\beta^{2}\right)}\left(\frac{\alpha \operatorname{Sinh} \beta}{\beta}+\mathrm{e}^{-\alpha}+\frac{\mathrm{f}}{\beta^{2}}\right) ;\right. \\
& \mathrm{C} 2=\frac{1}{\beta}\left(-\frac{\mathrm{BM}}{\mathrm{M}^{2}-\beta^{2}}+\frac{\alpha \mathrm{W}_{\mathrm{e}} \mathrm{a}_{0}}{\left(\alpha^{2}-\mathrm{M}^{2}\right)\left(\alpha^{2}-\beta^{2}\right)}\right)
\end{aligned}
$$

$\mathrm{C}$ is the concentration of aerosols in the presence of chemical reaction.

The fluid is transported across the section of layer per unit breadth then the volumetric rate of the fluid is given by,

$$
\mathrm{M}=\mathrm{h} \int_{0}^{1} \mathrm{CVdy}
$$

Using equations (31) and (29), performing the integration and after simplification we get,

$$
\mathrm{M}=\frac{\mathrm{h}^{3}}{\mathrm{DL}} \mathrm{G} \frac{\partial \mathrm{C}}{\partial \xi}
$$


International Journal of Soft Computing, Mathematics and Control (IJSCMC),Vol. 4, No. 2, May 2015

We assume that the variation of $\mathrm{C}$ with $\xi$ are small compared to the longitudinal direction and if $\mathrm{C}_{\mathrm{m}}$ is the mean concentration over a section, then $\frac{\partial \mathrm{C}}{\partial \xi}$ is indistinguishable from $\frac{\partial \mathrm{C}_{\mathrm{m}}}{\partial \xi}$ (Taylor, 1953) so that (33) may be written as

$$
\mathrm{M}=\frac{\mathrm{h}^{3}}{\mathrm{DL}} \mathrm{G} \frac{\partial \mathrm{C}_{\mathrm{m}}}{\partial \xi}
$$

No material is lost in the process which is expressed by the continuity equation for $\mathrm{C}_{\mathrm{m}}$ namely

$$
\frac{\partial \mathrm{M}}{\partial \xi}=-\frac{2}{\mathrm{~L}} \frac{\partial \mathbf{C}_{\mathrm{m}}}{\partial \mathrm{t}}
$$

where $\frac{\partial}{\partial \mathrm{t}}$ represents differentiation with respect to time at point where $\xi$ is constant.

Equation (34) using (35)

$$
\begin{aligned}
& -\frac{2}{\mathrm{~L}} \frac{\partial \mathrm{C}_{\mathrm{m}}}{\partial \mathrm{t}}=\frac{\mathrm{h}^{3}}{\mathrm{DL}} \mathrm{G} \frac{\partial^{2} \mathrm{C}_{\mathrm{m}}}{\partial \xi^{2}} \\
& \frac{\partial \mathrm{C}_{\mathrm{m}}}{\partial \mathrm{t}}=\mathrm{D} * \frac{\partial^{2} \mathrm{C}_{\mathrm{m}}}{\partial \xi^{2}}
\end{aligned}
$$

where

$$
D^{*}=-\frac{h^{3}}{2 D} G
$$

\section{Case 2: $\beta=0$ (without chemical reaction)}

When $\beta=0$, equation (30) becomes

$$
\frac{\partial^{2} C_{0}}{\partial y^{2}}=Q_{0} V
$$

where $\mathrm{C}_{0}$ is the concentration of aerosols without chemical reactions and $\mathrm{Q}_{0}=\frac{\mathrm{h}^{2}}{\mathrm{DL}} \frac{\partial \mathrm{C}_{0}}{\partial \xi}$

The solution of equation (37) using the equation (29) is

$$
\mathrm{C}_{0}=\mathrm{Q}\left(\frac{\mathrm{A} \operatorname{CoshMy}}{\mathrm{M}^{2}}+\frac{\mathrm{BSinh} M y}{\mathrm{M}^{2}}+\frac{\mathrm{W}_{\mathrm{e}} \mathrm{a}_{0} \mathrm{e}^{-\alpha \mathrm{y}}}{\alpha^{2}\left(\alpha^{2}-\mathrm{M}^{2}\right)}-\frac{\mathrm{fy}^{2}}{2}\right)+\mathrm{f} 1 \mathrm{y}+\mathrm{f} 2
$$

where $\mathrm{f} 1=\frac{\mathrm{h}^{2}}{\mathrm{Q}}\left(\frac{\mathrm{W}_{\mathrm{e}} \mathrm{a}_{0}}{\alpha\left(\alpha^{2}-\mathrm{M}^{2}\right)}-\frac{\mathrm{B}}{\mathrm{M}}\right)$; 


$$
\mathrm{f} 2=1-\frac{\mathrm{h}^{2}}{\mathrm{Q}}\left(\frac{\mathrm{ACoshMy}}{\mathrm{M}^{2}}+\frac{\mathrm{BSinh} M y}{\mathrm{M}^{2}}+\frac{\mathrm{W}_{\mathrm{e}} \mathrm{a}_{0} \mathrm{e}^{-\alpha}}{\alpha^{2}\left(\alpha^{2}-\mathrm{M}^{2}\right)}+\frac{\mathrm{f}}{2}+\frac{\mathrm{W}_{\mathrm{e}} \mathrm{a}_{0}}{\alpha^{2}\left(\alpha^{2}-\mathrm{M}^{2}\right)}+\frac{\mathrm{B}}{\mathrm{M}}\right)
$$

Following the same procedure explained in Case 1, we get

$$
\begin{aligned}
& \mathrm{M}_{0}=\mathrm{h} \int_{0}^{1} \mathrm{C}_{0} \mathrm{Vdy} \\
& \mathrm{M}_{0}=\frac{\mathrm{h}^{3}}{\mathrm{DL}} \mathrm{G}_{0} \frac{\partial \mathrm{C}_{0}}{\partial \xi}
\end{aligned}
$$

From equation (36) we get

$$
\frac{\partial \mathrm{C}_{\mathrm{m}}}{\partial \mathrm{t}}=\mathrm{D} 1 * \frac{\partial^{2} \mathrm{C}_{\mathrm{m}}}{\partial \xi^{2}}
$$

where, $\mathrm{D} 1^{*}=\frac{\mathrm{h}^{3}}{2 \mathrm{D}} \mathrm{G}_{0}$

which is the equation of the longitudinal dispersion. From equations (36a) and (40a), the lengthy expression of dispersion coefficients $\mathrm{D}^{*}$ and $\mathrm{D} 1^{*}$ are computed and the results obtained from the study are discussed in the next section.

\section{RESULTS AND DISCUSSIONS}

The dispersion of atmospheric aerosols under the effects of eletric and magnetic field is discussed analytically using Taylor analysis. Numerical evaluation of the analytical results reported in the previous section is performed using MATHEMATICA 8.0 and a representative set of results are displayed graphically through figures 2 to 11 . These results are obtained to illustrate the influence of electric and Hartmann numbers on velocity and dispersion coefficient.

Figures 2 and 3 show the velocity profiles for different electric number and Hartmann number. Figure 2 indicates that an increase in electric number results in increasing velocity and figure 3 shows that increasing Hartmann number decreases the velocity.

The dominant dispersion coeficient given in equation (36a) and (40a) is computed for different values of Hartmann number, electric number and reaction rate which are graphically represented in figures 4 to 11 .

Figures 4 and 5 represent the effect of reaction rate $\beta$ and electric number We on dispersion coefficient $D^{*}$ with Hartmann number $M$. It shows that $D^{*}$ decreases with an increase in Hartmann number $\mathrm{M}$ and reaction rate $\beta$ and $\mathrm{D}^{*}$ increases with increase in electric number We. 
International Journal of Soft Computing, Mathematics and Control (IJSCMC),Vol. 4, No. 2, May 2015

Figures 6 and 7 represent the dispersion coefficient $D^{*}$ with reaction rate $\beta$ for different values of Hartmann number $\mathrm{M}$ and electric number We. It is observed that $\mathrm{D}^{*}$ decreases with an increase in reaction rate $\beta$, Hartmann number $M$ and increases with increase in electric number We.

Figures 8 and 9 represent the dispersion coefficient $\mathrm{D}^{*}$ with electric number We for different values of reaction rate $\beta$ and Hartmann number $M$. It is observed that $D^{*}$ increases with an increase in electric number $\mathrm{We}$ and decreases with increases in reaction rate $\beta$ and Hartmann number $\mathrm{M}$.

From the figures 4 to 9 , it is found that the dispersion coefficient $\mathrm{D}^{*}$ increases with increases in electric number We and dispersion coefficient $\mathrm{D}^{*}$ decreases with increase in Hartmann number $\mathrm{M}$ and reaction rate $\beta$.

Figures 10 and 11 reveal that the dispersion coefficient $\mathrm{D} 1{ }^{*}$ increases with increase in electric number We and dispersion coefficient $\mathrm{D}{ }^{*}{ }^{*}$ decreases with increase in Hartmann number $\mathrm{M}$.

\section{ConClusions}

From the figures, it is concluded that for both with and without chemical reaction the electric field enhances the transport of aerosols and the magnetic field decreases the transport of aerosols. Also the increase in reaction rate parameter decreases the transport of aerosols. The mathematical model presented here suggests that the dispersion of atmospheric aerosols would depend upon the types of pollutants and other parameters in the atmosphere.
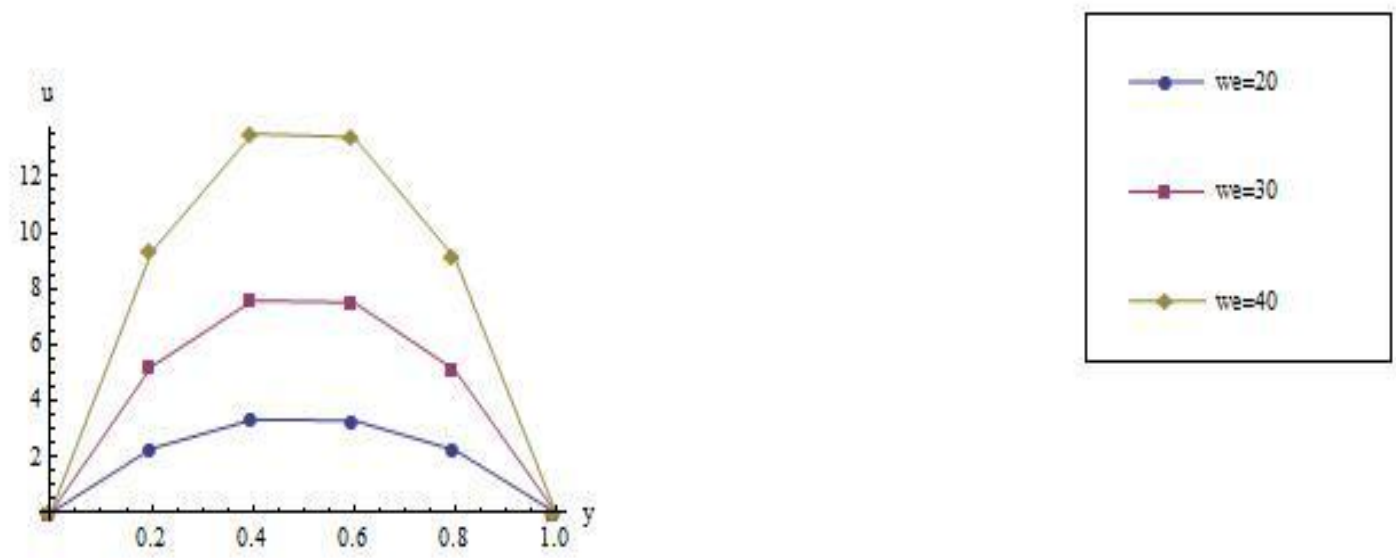

Figure 2. Effects of electric number We on velocity profile 
International Journal of Soft Computing, Mathematics and Control (IJSCMC),Vol. 4, No. 2, May 2015
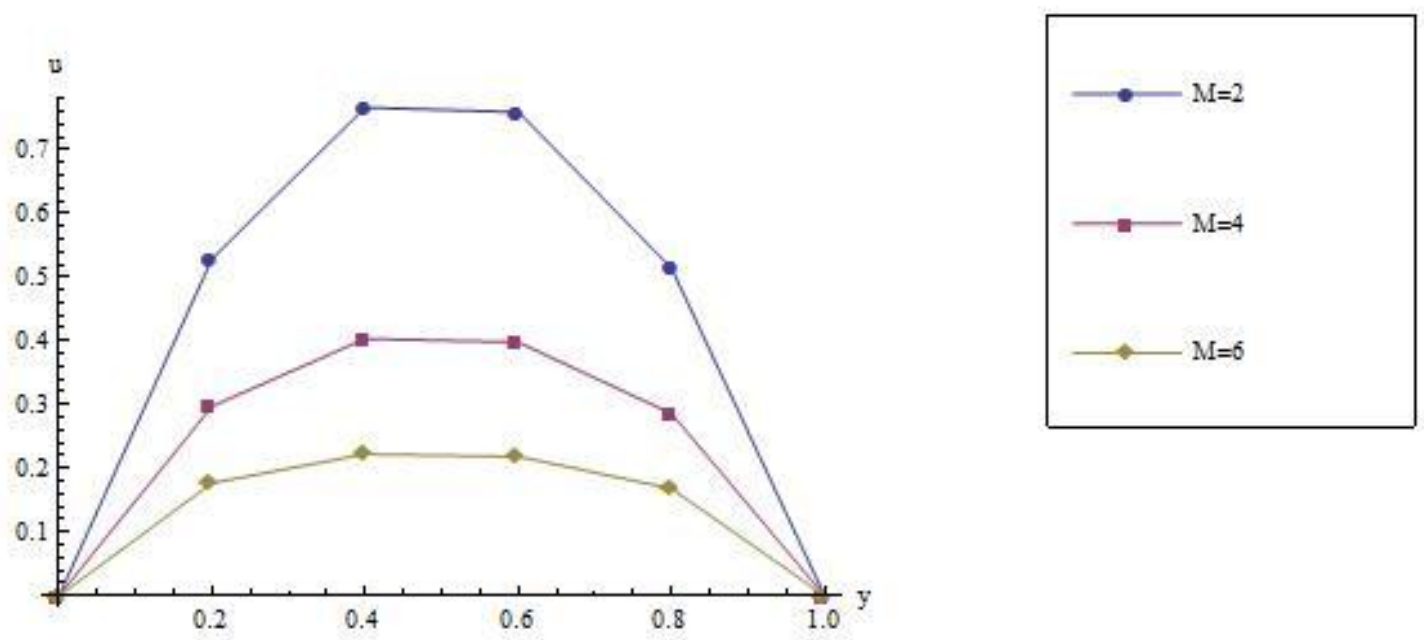

Figure 3. Velocity profiles for different values of Hartmann number M
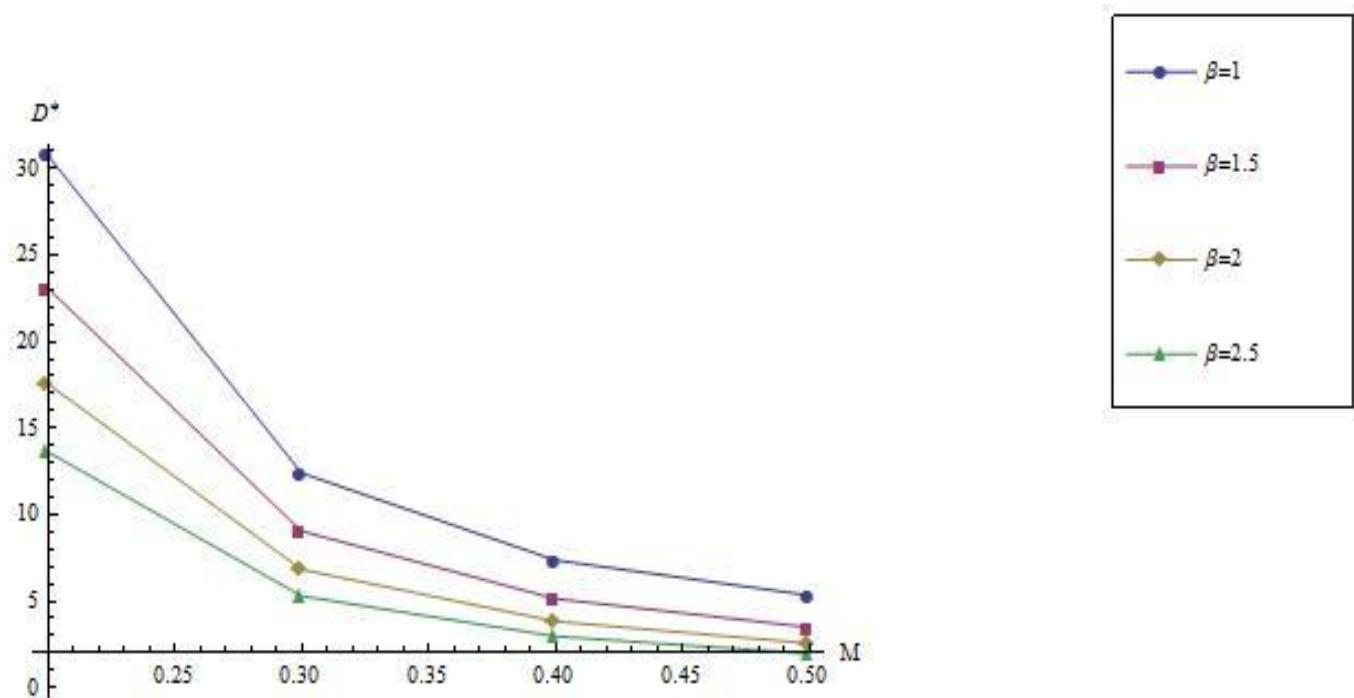

Figure 4. Effect of reaction rate $\beta$ on dispersion coefficient $D^{*}$ with Hartmann number $M$ for fixed value of electric number $\mathrm{We}=20$ 
International Journal of Soft Computing, Mathematics and Control (IJSCMC),Vol. 4, No. 2, May 2015

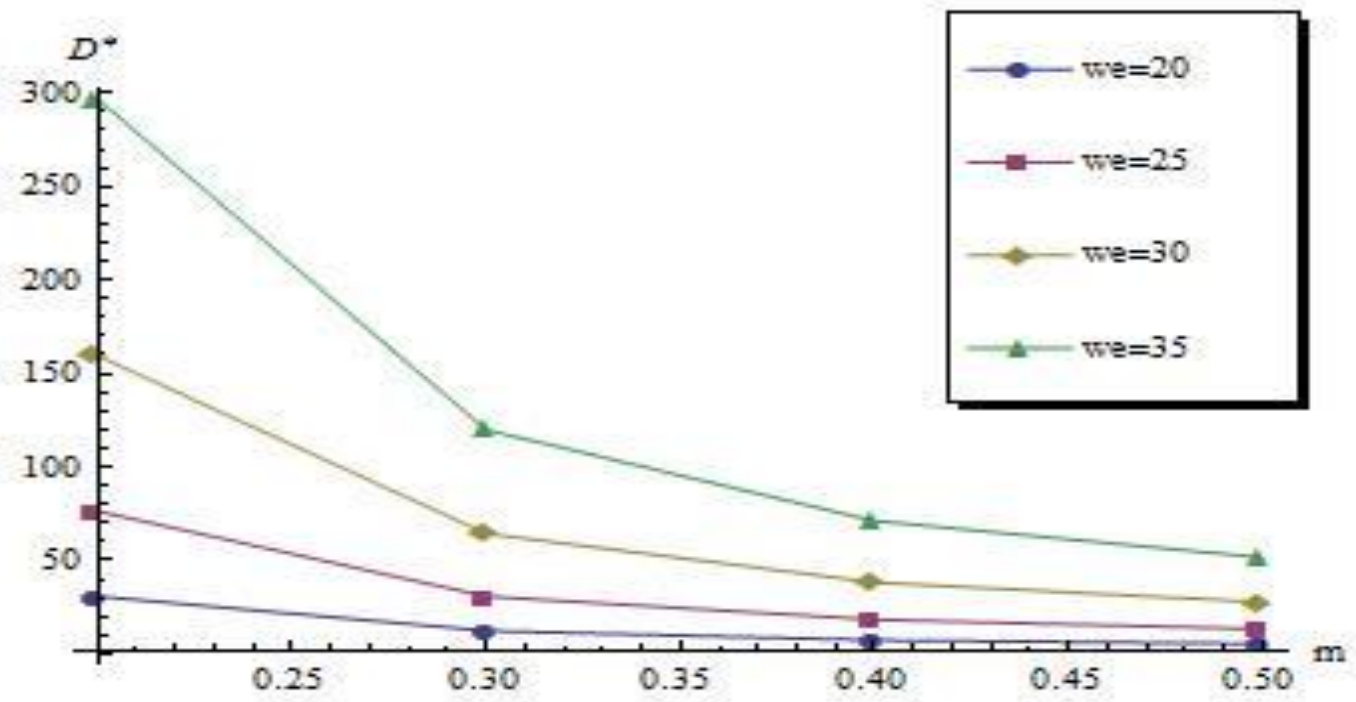

Figure 5. Dispersion coefficient $D^{*}$ versus Hartmann number $\mathrm{M}$ for different values of electric number We and for fixed value of reaction rate $\beta=1$ 
International Journal of Soft Computing, Mathematics and Control (IJSCMC), Vol. 4, No. 2, May 2015

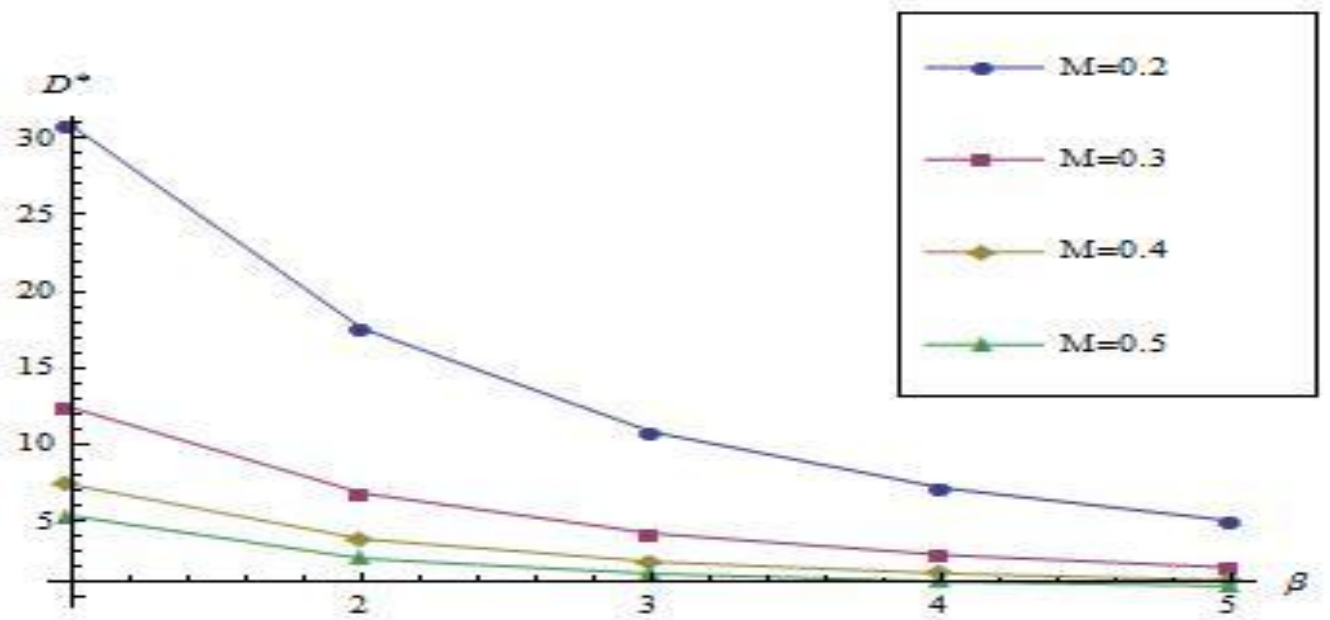

Figure 6. Dispersion coefficient $\mathrm{D}^{*}$ with reaction rate $\beta$ for different values of Hartmann number $\mathrm{M}$ and fixed value of electric number $\mathrm{We}=20$
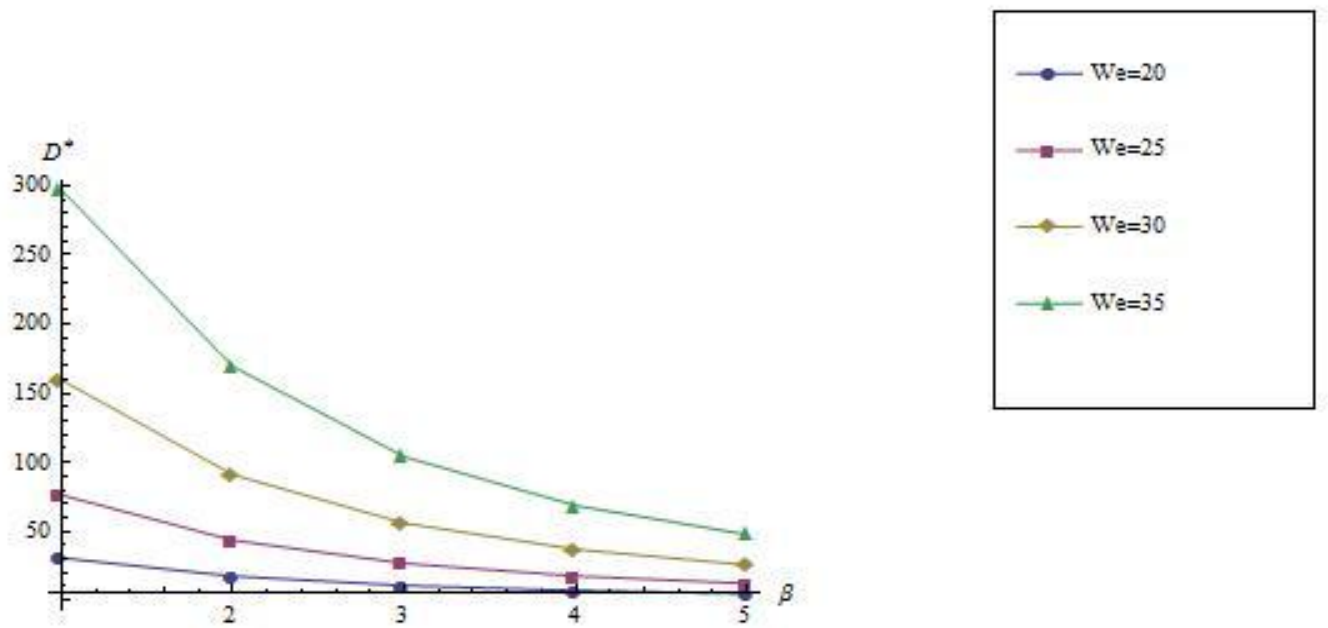

Figure 7. Dispersion coefficient $\mathrm{D}^{*}$ versus reaction rate $\beta$ for different values of electric number $\mathrm{We}$ and for fixed value of Hartmann number $M=0.2$ 
International Journal of Soft Computing, Mathematics and Control (IJSCMC), Vol. 4, No. 2, May 2015

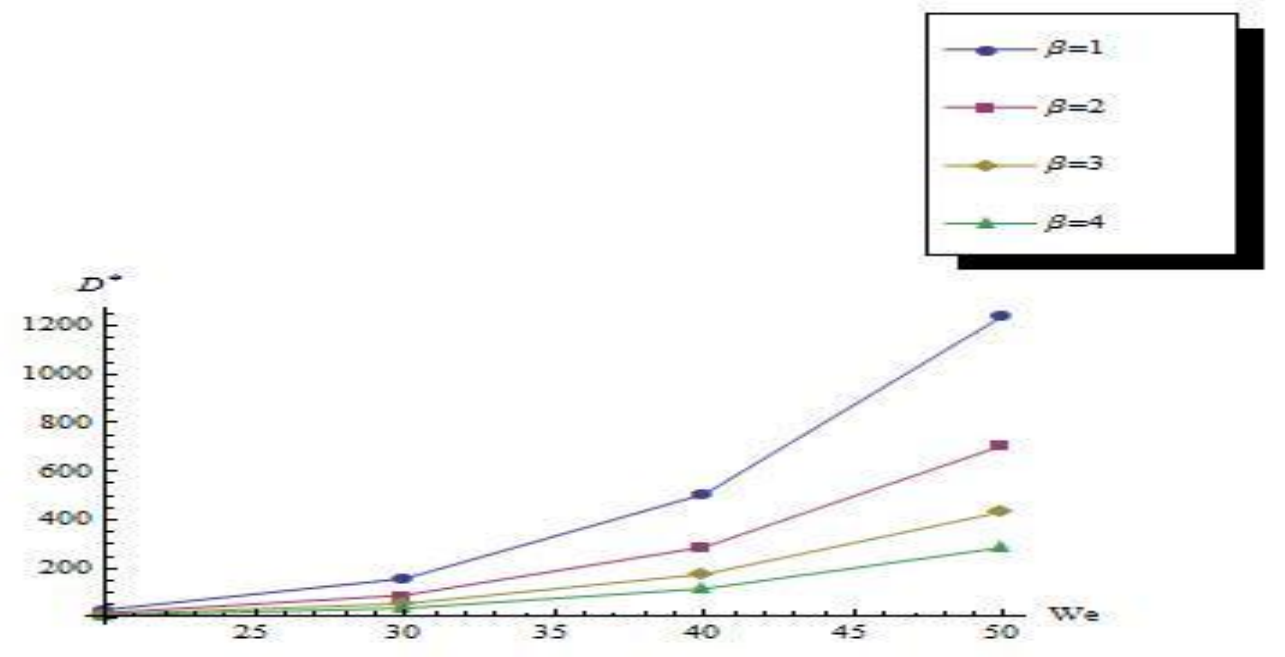

Figure 8. Dispersion coefficient $D^{*}$ versus electric number We for different values of reaction rate $\beta$ and for fixed value of Hartmann number $\mathrm{M}=0.2$

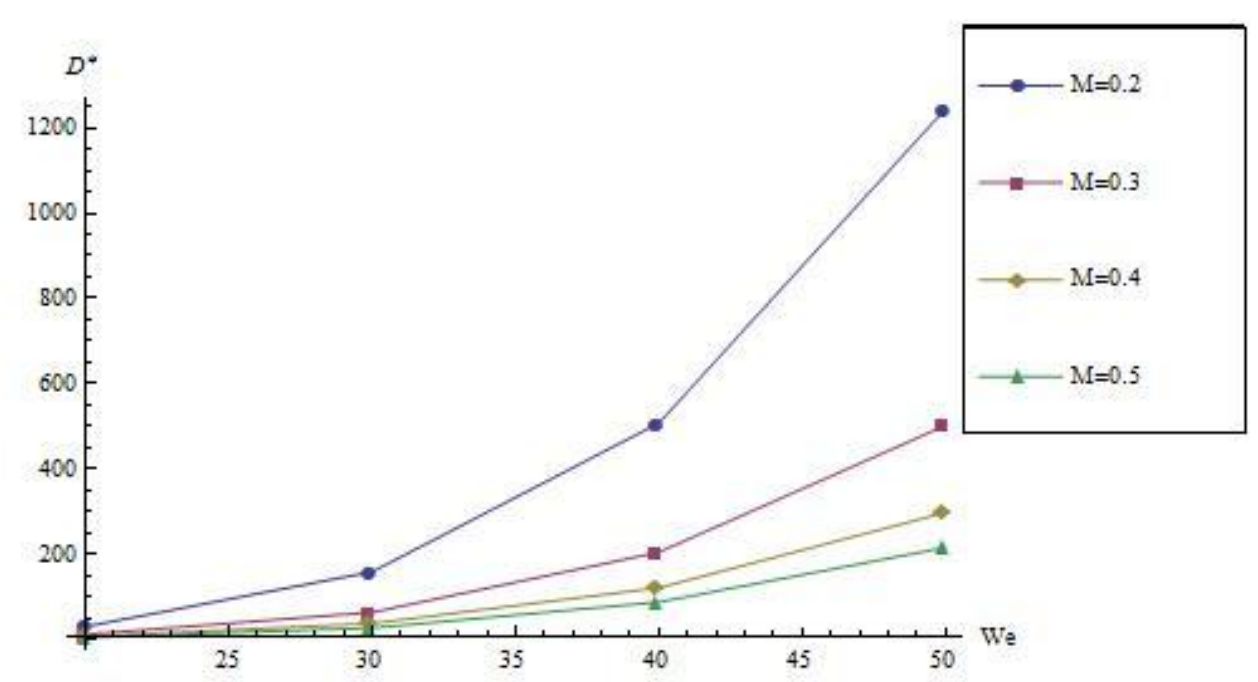

Figure 9. Dispersion coefficient $\mathrm{D}^{*}$ with electric number We for different values of Hartmann number M and for fixed value of reaction rate $\beta=1$ 
International Journal of Soft Computing, Mathematics and Control (IJSCMC), Vol. 4, No. 2, May 2015

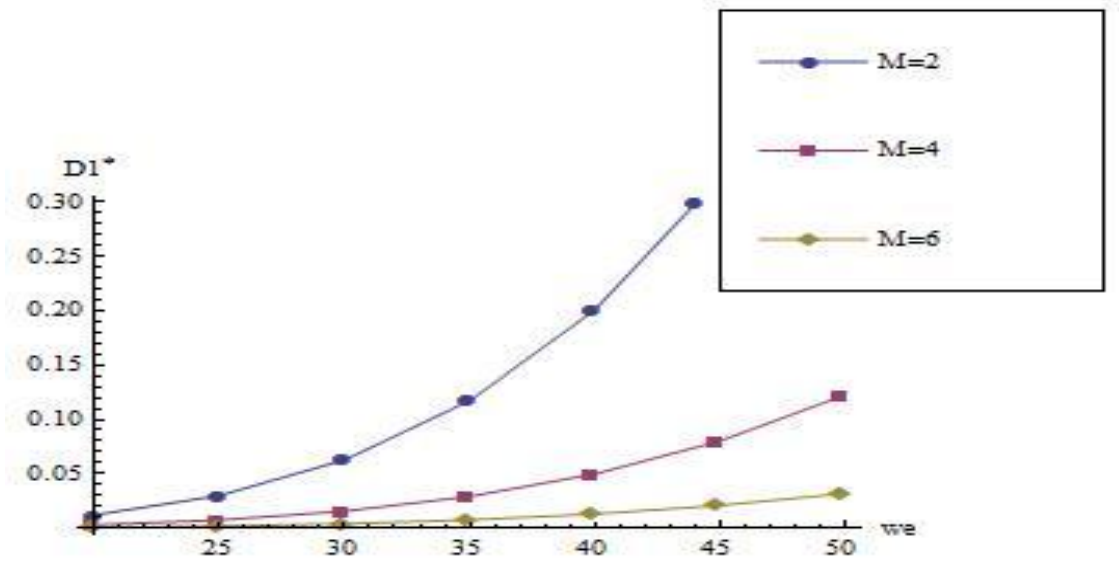

Figure 10. Dispersion coefficient D1* with Hartmann number M for different values of electric number for $\beta=0$

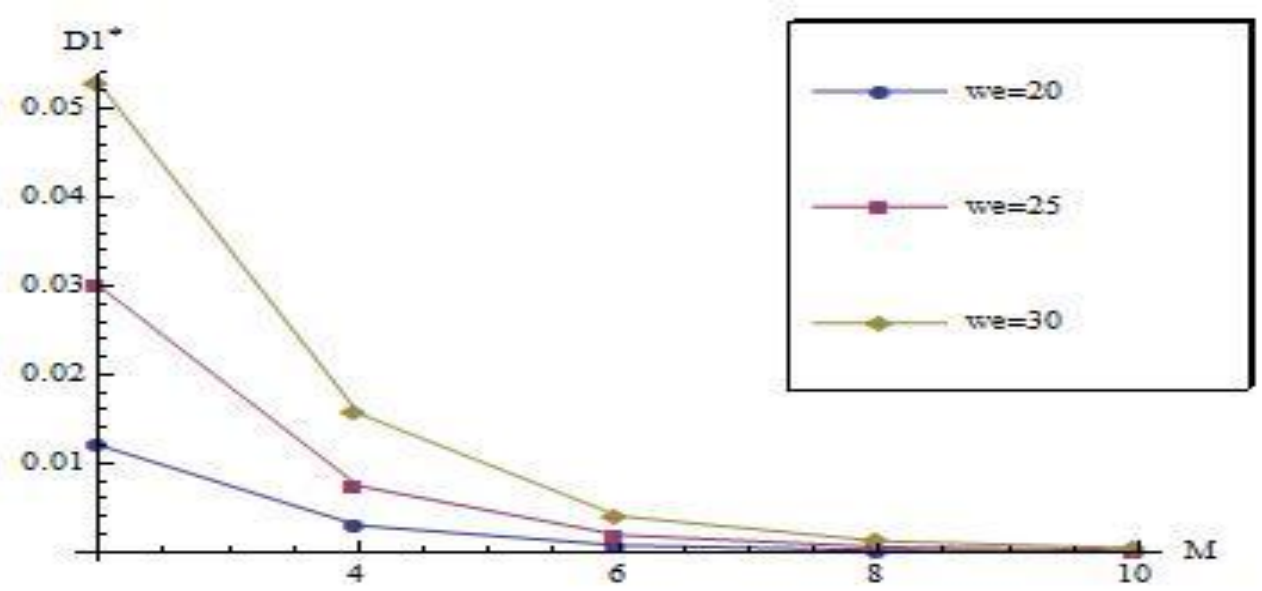

Figure 11. Dispersion coefficient D1* with electric number We for different values of Hartmann number M for $\beta=0$

\section{REFERENCES}

[1] Ansmann A., Althaussen D., Wandinger U., Franke K., Muller D, Wagner F. and Heintzenberg J., (2000), Vertical profiling of the Indian aerosol plume with six-wave length lidar during INDOEX: A first case study, Geophys. Res. Lett., 27(7): pp. 963-966

[2] Anttilla T., Kiendler-Scharr A., Tillmann R. and Mental T., (2006), On the reactive uptake of gaseous compounds by organic coated aerosols: theoretical analysis and application to the heterogenous hydrolysis of N2O5, Journal of Physics and Chemistry, A110, pp. 10435-10443.

[3] Brasseur G.P., Schultz M., Granier C., Saunois M., Diehl T., Botzet M., Roeckner E. and Walters S., (2006), Impact of climate change on the future chemical composition of the global temperature, Journal of Climatology, 19, pp. 3932-3951.

[4] Das S., Maji S.L., Guria M. and Jana R.N., (2009), Unsteady MHD Couette flow in a rotating system, Math. Comp. Modelling, 50, pp. 1211-1217.

[5] Gupta P.S. and Gupta A.S., (1972), Effect of homogeneous and heterogeneous reactions on the dispersion of a solute in the laminar flow between two plates. Proc. Roy. Soc. London, A 330, 59-63.

[6] Guria M., Das S., Jana R.N. and Ghosh S.K., (2009), Oscillatory couette flow in the presence of an inclined magnetic field, Meccanica, 44, pp. 555-564. 
International Journal of Soft Computing, Mathematics and Control (IJSCMC),Vol. 4, No. 2, May 2015

[7] Kazuhide Ito and Hiroshi Harashima, (2011), Coupled CFD analysis of size distributions on indoor secondary organic aerosol derived from ozone reactions, building and environment, 46(3), pp. 711 718 .

[8] Meena Priya P. and Nirmala P. Ratchagar, (2013), Coagulation and condensation of aerosols in atmospheric dispersion model, The Journal of Computational Multiphase Flows, 5(2), pp. 115-138.

[9] Muller D., Franke K., Wagner F., Althausen D., Ansmann A. and Heintzenberg J., (2001), Vertical profiling of optical and physical particle properties over the tropical Indian ocean with six wavelength lidar, J. Geophys. Res., 106(D22), pp. 28567-28575.

[10]Niranjan K., Madhavan B.L. and Sreekanth V., (2007). Micro pulse lidar observation of high altitude aerosol layers at Visakhapatnam located on the east coast of India, Geophys. Res. Lett., 34, L03815.

[11] Pal D., (1999), Effect of chemical reaction on the dispersion of a solute in a porous medium, Applied Mathematical Modeling, 23, pp. 557-566.

[12] Ramana M.V., Ramanathan V. and Podgomy I.A., (2004), The direct observations of large aerosol radiative forcing in the Himalayan region, Geophys. Res. Lett., 31, L05111.

[13] Rudraiah N., Pal D. and Siddheshwar, P.G., (1986), Effect of couple stress on the unsteady convective diffusion in fluid flow through a channel. BioRheology, 23(4), pp. 349-358.

[14] Rudraiah N. and Ng, C.O., (2007), Dispersion in porous media with and without chemical reation: A review, Journal of Porous Media, 10(3), pp. 219-248.

[15] Satheesh S.K., Vinoj V. and Krishnamoorthy K., (2006), Vertical distribution of aerosols over an urban continental site in India inferred using a micro pulse lidar, Geophys. Res. Lett.,33(20), Art No. L20816.

[16] Shivakumar P.N., Rudraiah N., Pal D. and Siddheshwar P.G., (1987), Closed form solution for unstaedy diffusion in a fluid saturated sparsely packed porous medium, Int. Communications in Heat and Mass Transfer, 14, pp. 137-145.

[17] Stier J., Mental Th.F. and Wahner, A., (1996), Physical characterization of aerosols and heterogeneous reactions in a large atmospheric chamber, Nucleation and Atmospheric Aerosols, 96, pp. 566-569.

1[8] Taylor G.I., (1953), Dispersion of soluble matter in solvent flowing slowly through tube, Journal of Proc. Roy. Soc. London, A 219, pp. 186-203.

[19] Tripathi S.N., Dey S., Tare V. and Satheesh S.K., (2005), Aerosol black carbon radiative forcing at an industrial city in Northern India, Geophys. Res. Lett., 32(8), Art No. L08802.

\section{Author}

Dr.P. Meenapriya, completed her M.Sc. in Mathematics from Madurai Kamaraj University, Madurai, India and her Ph.D. in Mathematics from Annamalai University, India. At present, she is working as an Assistant Professor in Mathematics, Faculty of Engineering and Technology, Annamalai University, India. She has published more than 10 research papers in various International Journals and Conferences. Her area of interest is Fluid Dynamics. 